\title{
Impact of components of metabolic syndrome on the prostatic volume and lower urinary tract symptoms in a sample of patient with benign prostatic hyperplasia in Iraq
}

\author{
Dr. Ali Zuhair Khudhur ${ }^{1}$, Dr. Alaa Al-Deen Al-Dabbagh ${ }^{2 *}$ \\ ${ }^{1}$ Al-Yarmouk Teaching Hospital/Department of urology/Baghdad/Iraq. \\ ${ }^{2}$ Assistant professor at Al-Mustansiriyah University/College of Medicine/Department of surgery \\ /Baghdad / Iraq.
}

\section{Objective}

To evaluate the association between the components of metabolic syndrome (MetS) and lower urinary tract symptoms (LUTS) due to benign prostatic hyperplasia (BPH) focusing at their effects on prostatic volume and on the severity of LUTS.

\section{Patients \& Methods}

From October 2016 to January 2018, eighty patients presented with LUTS due to the BPH. LUTS were assessed using the international prostatic symptoms score (IPSS) and MetS was defined according to the National Cholesterol Education Program-Adult Treatment Panel III guidelines. Patients were randomly collected into two categories: A (48 patients) had MetS and B (32 patients) without MetS.

\section{Results}

The mean age was 64.3 years, statistically significant variation was identified between the two categories regarding the moderate and severe IPSS, S.PSA, prostatic size and post voiding residue $(P V R)$, the $P$ value $(<0.05)$. The most frequent MetS components were: hypertension in $65 / 80$ patients (81.25\%), high fasting glucose in $49 / 80$ patients $(61,25 \%)$, and waist circumference elevation in $55 / 80$ patients $(68.75 \%)$. The association between MetS components, the prostatic volume and severity of LUTS had shown that all MetS components except HDL-cholesterol were significantly correlated with higher prostatic volume $(P<0.05)$. Also a positive statistically significant association was discovered between each component of MetS and higher IPSS, excepting HDL-cholesterol $(P=0.93)$ and triglyceride $(P=0.58)$.

\section{Conclusion}

The results of the present study confirmed that there is a significant relation between the components of metabolic syndrome, the increase in prostatic volume and the severity of LUTS/BPH.
Keywords: LUTS; BPH; MetS; prostatic volume

*Correspondence to Author:

Dr. Alaa Al-Deen AL-Dabbagh

Assistant professor at Al-Mustansiriyah University/College of Medicine/ Department of surgery / Baghdad / Iraq.

How to cite this article:

Ali Zuhair Khudhur, Alaa AlDeen Al-Dabbagh. Impact of components of metabolic syndrome on the prostatic volume and lower urinary tract symptoms in a sample of patient with benign prostatic hyperplasia in Iraq. Global Journal of Urology and Nephrology, 2019,

\section{$2: 17$}

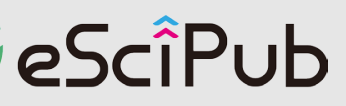

eSciPub LLC, Houston, TX USA. Website: http://escipub.com/ 


\section{Introduction}

Benign Prostatic .Hyperplasia (BPH) is an advancing disease with a peak age of onset at 80 years, recognized by enlargement of the prostate .along with lower urinary tract symptoms (LUTS) ${ }^{[1,2]}$ which could results in chronic UTI, acute urinary retention, renal failure, incontinence of urine \& the necessity for $\mathrm{BPH}$ related surgery $[3,4]$.

Metabolic syndrome is a cluster of medical conditions which include elevated triglycerides, arterial hypertension, impaired glucose metabolism, low High Density Lipoprotein (HDL) and abdominal obesity [5].

Evidences have underlined an emerging link between MetS, benign prostatic enlargement and its related lower urinary tract symptoms ${ }^{[6-8]}$.

Among Mets features, insulin resistance and secondary hyperinsulinaemia have a role with an increased risk of $\mathrm{BPH}{ }^{[9]}$. Reduced $\mathrm{HDL}$ and increased triglyceride levels were considerably linked to higher prostatic inflammation which is directly related to prostate enlargement [10] inducing $\mathrm{BPH}$ which is a main cause of bladder outlet obstruction triggering LUTS ${ }^{[5]}$.

Besides age, LUTS and MetS also participate in a variety of other risk factors, such as obesity, hyperglycemia, hypertension, lack of androgen, depression, and smoking, consequently indicating that metabolic syndrome might have a major role in the pathogenesis of LUTS ${ }^{[11]}$ A link between metabolic syndrome and prostate growth rate has also been found in clinical series [12, 13]. All these findings point out that the MetSrelated BPH/ LUTS should be counted as potentially objective therapy in order to oppose the resulting prostate rapid growth ${ }^{[14]}$ The objective of the present study was to evaluate the effects of MetS on the prostatic volume and LUTS/BPH in a sample of Iraqi men aged $>50$ years.

\section{Patients \&methods}

From October 2016 to January 2018, [80 patients (with an age range: $50-85$ years)], presented to the urology consultation department of Al-Yarmouk Teaching Hosptital/Baghdad/Iraq with LUTS due to the BPH (Prostatic volume $>30 \mathrm{ml}$ was considered prostatic hyperplasia) ${ }^{[15]}$.

Assessment of patients included history taking regarding general patient health and voiding status, assessesd by IPSS, clinical general examination including waist circumference and digital rectal examination in all patients, laboratory investigations including $\mathrm{CBC}$, urinalysis, urine culture and sensitivety, blood urea, serum creatinine, fasting blood sugar, PSA, lipid profile ( S. cholesterol, triglyceride, LDL ,HDL ). Transabdominal ultrasound (performed by the same operator) to measure the post void residual urine volume \& prostatic size according to using the equation: Width $x$ height $x$ length $x$ 0.52. Uroflowmetry to determine the maximum urine flow rate $(Q$ max) at a voided volume of $>150 \mathrm{ml}$. Inclusion criteria included age $>50$ year, Patient had both LUTS and $\mathrm{BPH}$ and no drugs taken for urinary symptoms.

Exclusion criteria: neurological disorders, renal insufficiency, urinary tract infection, bladder calculi, prostatic tumors, urethral stricture and previous pelvic surgery or radiotherapy.

Informed consents were obtained from all patients before enrolling in this study.

Then patients were divided into two groups; group A 48 patients with MetS and group B 32 patients without MetS.

MetS was determined in agreement with the USA National Cholesterol Education Program - Adult Treatment Panel III(NCEPATPIII), by the existence of three or more of the following: central obesity (waist circumference of $\geq 102 \mathrm{~cm}$ ), elevated triglycerides $(\geq 1.7 \mathrm{mmol} / \mathrm{L}$ or $150 \mathrm{mg} / \mathrm{dL}$ ), elevated blood pressure $(\geq 130 / 85 \mathrm{mmHg})$, or patients on 
antihypertensive drugs, elevated fasting glucose ( $\geq 6.1 \mathrm{mmol} / \mathrm{L}$ or $110 \mathrm{mg} / \mathrm{dL})$, or patients on antidiabetic drugs, reduced HDL cholesterol ( $<1.03 \mathrm{mmol} / \mathrm{L}$ or $40 \mathrm{mg} / \mathrm{dL})$ [16]. The severity of LUTS was evaluated accord-ing to IPSS. The questionnaire was setup on seven questions. LUTS was classified as none/mild (0-7), moderate (8-19), or severe (20-35). Utilizing this questionnaire, symptoms were subdivided into three classes; voiding, storage and post micturition symptom$\mathrm{s}^{[17] \text {. }}$

This study was approved by the ethical committee of the institute (Ministry of Health/ The Arab board for health specializations in Iraq/Al-Yarmouk Teaching center, Baghdad) Statistical analysis was performed using students T-test and one way analyses of variance (ANOVA) and chi-squared, post analysis was used to test the difference in outcome between deferent groups, where appropriate, using Statistical Package for Social Sciences (SPSS), version 16(Chicago,IL). Data were presented as mean + standard deviation or as number and percentage. A probability $(P)$ value of less than 0.05 was considered statistically significant.

\section{Results}

During the study period, eighty patients
\{ forty eight $(60 \%)$ with MetS and the other thirty two patients (40\%) without MetS \} were evaluated, their mean age was 64.3 years, focusing on the effects of MetS and its components on the severity of the LUTS and on the prostatic volume.

In the comparison of the two groups as summarized in Table $\mathbf{1}$ and Figures 1.

Regarding the patients with MetS the mean age in this study was $62.5 \pm 6.4$ years. Mild, moderate and severe LUTS were found in $25 \%(12 / 48), 43.75 \%(21 / 48)$ and $31.25 \%$ (15/48) patients respectively.

The mean prostatic size in this group was $60.6 \pm 20 \mathrm{ml}$. While in patients without MetS the mean age was $67.2 \pm 6.1$ years. Eleven (34.37\%) patients had mild LUTS, thirteen $(40.62 \%)$ patients had moderate LUTS and eight ( $25 \%)$ patients had severe LUTS. The mean prostatic size in this group was 49.2 $\pm 15.9 \mathrm{ml}$.

Statistically significant variation was detected between the two groups regarding the moderate and severe IPSS, PSA, prostatic size and PVR, where men with Mets had significantly greater mean IPSS, more severe LUTS and higher PSA, prostatic size and PVR than those without Mets, the $\boldsymbol{P}$ value $(<0.05)$. Conversely there was no statistically significant variance regarding the mild IPSS and Qmax.

\begin{tabular}{|c|c|c|c|}
\hline Variables & $\begin{array}{c}\text { Group A } \\
\text { Patients with Mets } \\
\mathrm{N}=48(60 \%)\end{array}$ & $\begin{array}{c}\text { Group B } \\
\text { Patients without Mets } \\
\mathrm{N}=32(40 \%)\end{array}$ & $P$ value \\
\hline $\begin{array}{l}\text { age (year ) } \\
\text { mean } \pm S D\end{array}$ & $62.5 \pm 6.4$ & $67.2 \pm 6.1$ & 0.02 \\
\hline $\begin{array}{l}\text { PSA }(\mathrm{ng} / \mathrm{mL}) \\
\text { mean } \pm \text { SD }\end{array}$ & $2.3 \pm 0.6$ & $1.7 \pm 0.4$ & 0.02 \\
\hline $\begin{array}{l}\text { Prostatic size }(\mathrm{ml}) \\
\text { mean } \pm \mathrm{SD}\end{array}$ & $60.6 \pm 20$ & $49.2 \pm 15.9$ & 0.02 \\
\hline $\begin{array}{l}\text { PVR }(\mathrm{mL}) \\
\text { mean } \pm S D\end{array}$ & $44.8 \pm 7.9$ & $30.2 \pm 6.8$ & 0.01 \\
\hline $\begin{array}{l}\text { Mild IPSS } N(\%) \\
\text { mean score } \pm S D\end{array}$ & $\begin{array}{c}12(25.00 \%) \\
5.6 \pm 0.9\end{array}$ & $\begin{array}{c}11(34.37 \%) \\
5.1 \pm 1.4\end{array}$ & 0.34 \\
\hline $\begin{array}{l}\text { Moderate IPSS } N(\%) \\
\text { mean score } \pm S D\end{array}$ & $\begin{array}{c}21(43.75 \%) \\
14.8 \pm 1.8\end{array}$ & $\begin{array}{c}13(40.62 \%) \\
13.1 \pm 2.3\end{array}$ & 0.04 \\
\hline $\begin{array}{l}\text { Severe IPSS } N(\%) \\
\text { mean score } \pm \text { SD }\end{array}$ & $\begin{array}{c}15(31.25 \%) \\
27.6 \pm 2\end{array}$ & $\begin{array}{c}8(25.00 \%) \\
23.8 \pm 2.8\end{array}$ & 0.01 \\
\hline $\begin{array}{l}\text { Qmax }(\mathrm{mL} / \mathrm{s}) \\
\text { mean } \pm S D\end{array}$ & $15.8 \pm 3.1$ & $16.9 \pm 2.8$ & 0.36 \\
\hline
\end{tabular}

GJUN: https://escipub.com/global-journal-of-urology-and-nephrology/ 
Table 1: Comparison of the effects of MetS on the prostatic volume and the severity of LUTSIBPH, between the two groups.

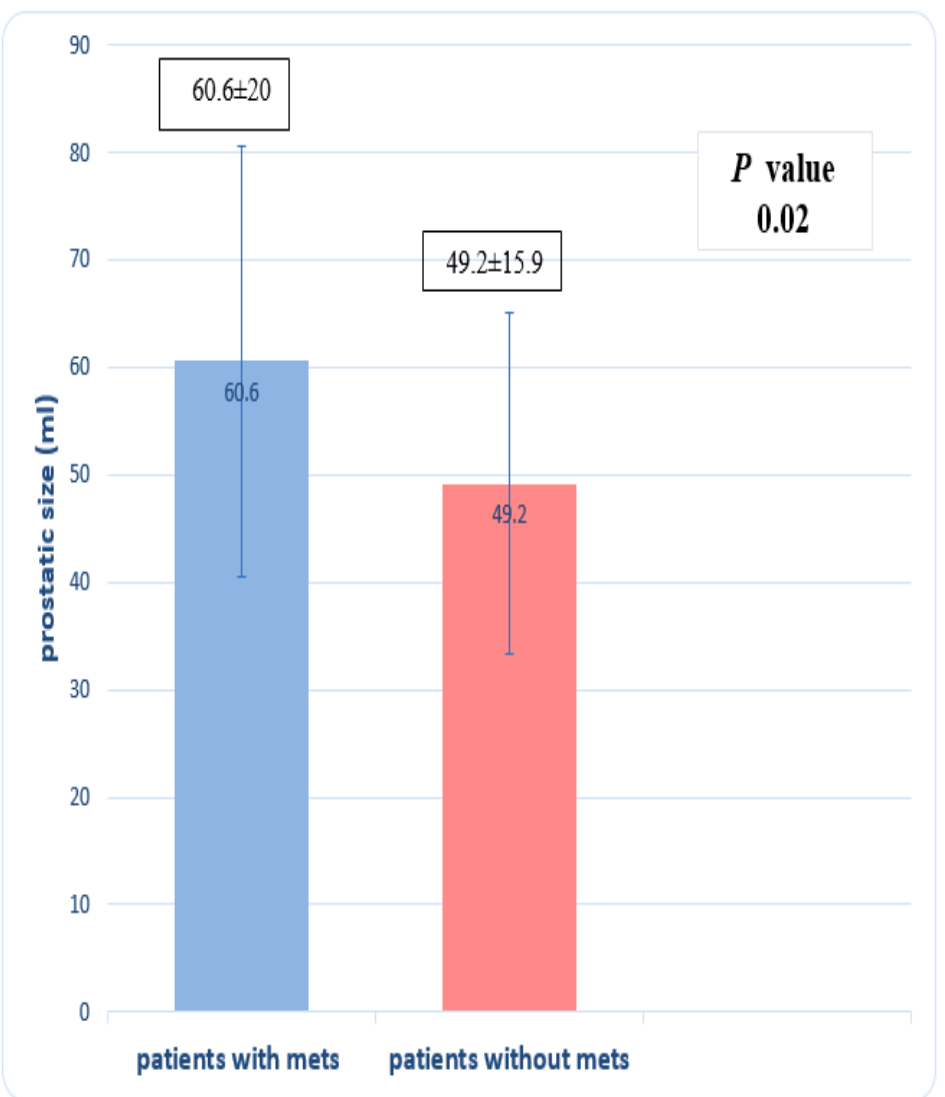

Figure 1: Comparison of the mean of prostatic size in patients' with and without MetS.

The frequency of Mets components were listed in Figure 2, Table 2. Hypertension was found in $65 / 80(81.25 \%)$, high fasting blood glucose in $49 / 80(61.25 \%)$ and waist circumference elevation in 55/80 (68.75\%) patients. These three components were the most often recorded criteria of metabolic syndrome.

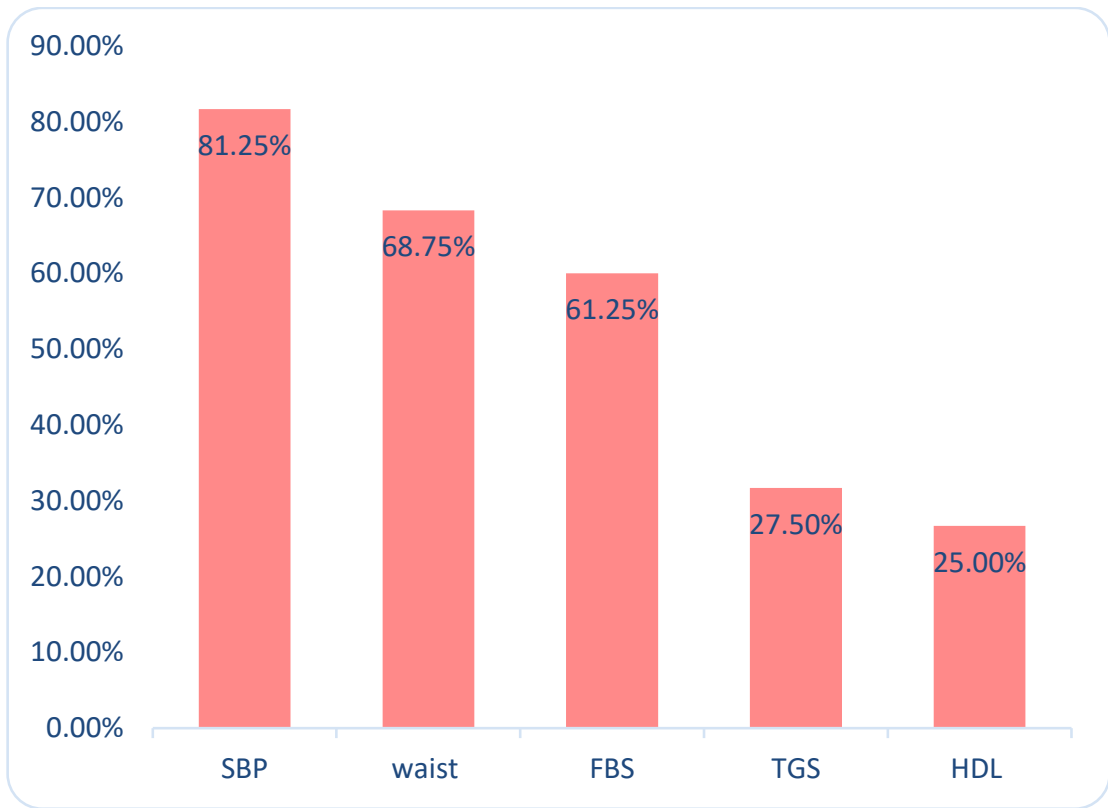

Figure 2: The frequency of components of metabolic syndrome 


\begin{tabular}{|c|c|c|}
\hline The metabolic syndrome criteria & Number of patients & Percentage of patients \\
\hline SBP ( $\geq 130 / 85 \mathrm{mmHg}$ ) & $65 / 80$ & $81.25 \%$ \\
\hline Waist ( $\geq 102 \mathrm{~cm}$ ) & $55 / 80$ & $68.75 \%$ \\
\hline FBS ( $\geq 110 \mathrm{mg} / \mathrm{dL}$ ) & $49 / 80$ & $61.25 \%$ \\
\hline TGS ( $\geq 150 \mathrm{mg} / \mathrm{dL}$ ) & $22 / 80$ & $27.50 \%$ \\
\hline $\mathrm{HDL}(\leq 40 \mathrm{mg} / \mathrm{dL})$ & $20 / 80$ & $25,00 \%$ \\
\hline
\end{tabular}

Table 2: The frequency of components of MetS.

The association between metabolic syndrome components, the prostatic size and the severity of LUTS/BPH was shown in Table 3 and 4. All MetS components except HDLcholesterol were significantly correlated with higher prostatic volume $(P<0.05)$. Also a positive statistically significant association was identified between each component of MetS and higher IPSS, except for HDLcholesterol $(P=0.93)$ and triglyceride $(P=$ 0.58).

\begin{tabular}{|c|c|c|c|}
\hline Metabolic syndrome components & $\mathrm{N}=80$ & Prostatic size mean (ml) & $p$ \\
\hline $\begin{array}{l}\text { Waist circumference }(\mathrm{cm}) \\
\geq 102 \\
<102\end{array}$ & $\begin{array}{l}55 \\
25\end{array}$ & $\begin{array}{l}56.8 \\
45.8\end{array}$ & 0.018 \\
\hline $\begin{array}{l}\text { Blood pressure }(\mathrm{mm} / \mathrm{Hg}) \\
\geq 130 / 85 \\
<130 / 85\end{array}$ & $\begin{array}{l}65 \\
15\end{array}$ & $\begin{array}{l}63.5 \\
50.5\end{array}$ & 0.004 \\
\hline $\begin{array}{l}\text { HDL cholesterol }(\mathrm{mg} / \mathrm{dl}) \\
\leq 40 \\
>40\end{array}$ & $\begin{array}{l}20 \\
60\end{array}$ & $\begin{array}{l}56.4 \\
54.1\end{array}$ & 0.65 \\
\hline $\begin{array}{l}\text { Serum triglyceride }(\mathrm{mg} / \mathrm{dl}) \\
\geq 150 \\
<150\end{array}$ & $\begin{array}{l}22 \\
58\end{array}$ & $\begin{array}{l}61.1 \\
52.1\end{array}$ & 0.02 \\
\hline $\begin{array}{l}\text { Fasting blood sugar }(\mathrm{mg} / \mathrm{dl}) \\
\geq 110 \\
<110\end{array}$ & $\begin{array}{l}49 \\
31\end{array}$ & $\begin{array}{l}58.7 \\
49.3\end{array}$ & 0.005 \\
\hline
\end{tabular}

Table 3: Prostatic size and its association with the components of MetS

\begin{tabular}{|l|c|c|c|c|}
\hline \multicolumn{1}{|c|}{$\begin{array}{c}\text { Metabolic syndrome } \\
\text { components }\end{array}$} & \multicolumn{3}{c|}{ IPSS } & P \\
\hline $\begin{array}{l}\text { Waist circumference (cm) } \\
\geq 102\end{array}$ & 19.51 & 58.54 & 21.95 & \\
$<102$ & 63.16 & 26.32 & 10.53 & 0.003 \\
\hline $\begin{array}{l}\text { Blood pressure (mm/Hg) } \\
\geq 130 / 85\end{array}$ & 27.66 & 53.19 & 19.15 & \\
\hline
\end{tabular}




\begin{tabular}{|l|c|c|c|c|}
\hline$<130 / 85$ & 69.23 & 23.08 & 7.69 & \\
\hline $\begin{array}{l}\text { HDL cholesterol (mg/dl) } \\
\leq 40\end{array}$ & 62.50 & 25.00 & 12.50 & 0.93 \\
$>40$ & 65.91 & 20.45 & 13.64 & 0.58 \\
\hline $\begin{array}{l}\text { Serum triglyceride (mg/dl) } \\
\geq 150\end{array}$ & 36.84 & 47.37 & 15.79 & 12.20 \\
\hline 150 & 51.22 & 36.59 & 10.20 & 0.036 \\
\hline $\begin{array}{l}\text { Fasting blood sugar (mg/dl) } \\
\geq 110\end{array}$ & 33.33 & 56.41 & 9.52 & \\
$<110$ & 66.67 & 23.81 & & \\
\hline
\end{tabular}

Table 4: The association between the components of MetS and the severity of LUTS/BPH.

\section{Discussion}

This study was designed to investigate the association between the components of metabolic syndrome (MetS) and the severity of lower urinary tract symptoms due to $\mathrm{BPH}$ and its effect on the prostatic volume.

In this study mean $( \pm S D)$ age was $62.5 \pm 6.4$ years in group $A$ and $67.2 \pm 6.1$ years in Group B and the variance was statistically significant $(P=0.02)$. This result was consistent with the reports of some investigators (Ford et al ${ }^{[18]}$ and Parsons et al ${ }^{[19]}$ ) but it differed from that of Isa et al [20]. It might be due to aging in addition to the effects of MetS components on the earlier progression of prostatic volume and on the earlier LUTS in our patients.

As evident in our study, Hypertension was found in 65/80 (81.25\%), high fasting blood glucose in 49/80 (61.25\%) and waist circumference elevation in 55/80 (68.75\%) patients. These three components were the most often recorded criteria of metabolic syndrome. Many other studies observed similar findings Hammarsten et al [21], Parsons et al [22].

In the present study, there was a positive correlation between elevating fasting blood glucose $(P=0.005)$, hypertension $(P=0.004$ ), central obesity (waist circumference) $(P=$ $0.018)$, elevating triglyceride $(P=0.02)$ and the higher prostatic volume and negative correlation with HDL-cholesterol $(P=0.65)$. These results were in agreement with many studies; Ozden et al [12], Parsons and colleagues [22], Hammarsten and colleagues [23] and Dahle et al ${ }^{24]}$ who demonstrated a positive relation between prostatic enlargement and MetS. However, Gupta et al [25] did not confirm an association between MetS and BPH.

The precise pathophysiology correlating LUTS and BPH to metabolic syndrome is still unclear. Many mechanisms were put in to explain this association; including insulin resistance with resulting hyperinsulinemia lead to increment in insulin growth factor favoring prostate growth and enlargement [21] and chronic prostatic inflammation inducing $\mathrm{BPH}$ development [10]

In this study, positive correlation between elevating fasting blood glucose $(P=0.036)$, hypertension $(P=0.022)$, central obesity (waist circumference) $(P=0.003)$ and higher IPSS score was identified and negative correlation with $\mathrm{HDL}$-cholesterol $(P=0.93)$ and triglyceride $(P=0.58)$. Several studies noticed comparable findings like De Nunzio et al, Hammarsten \& Peeker, Kirby et al, Pan et al, and Yang et al [26-30].

The pathophysiological hypothesis to explain the correlations between metabolic syn- 
drome and lower urinary tract symptoms include the effect of hyperglycemia on parasympathetic nerves in the pelvic ganglion, inducing apoptosis leading [31] to an oversupply of sympathetic activity compared to parasympathetic. In addition, hypertension has a role in increasing sympathetic tone and function of a1-adrenoreceptor ${ }^{[32]}$.

This increase in sympathetic tone may lead to increased bladder neck obstruction and reduced bladder contractility power, resulting in increased lower urinary tract symptoms as demonstrated in our study.

However, this association between metabolic syndrome and lower urinary tract symptoms was not supported by a study made by Gao et al ${ }^{\text {[33] }}$ who found that no significance was detected in the severity of LUTS in men with MetS as compared to those without MetS. Nevertheless, it is difficult to compare their study with ours as their objects were the whole man population, regardless of $\mathrm{BPH}$ existence and their patients were younger (mean age was 39 versus 64.3 of the present study).

\section{Conclusion}

The results of the present study confirmed that there is a significant relationship between the components of metabolic syndrome, increment in prostatic volume and the severity of LUTS/BPH. Considering Mets as a group of variable factors and preventing such factors through dietary modification and practicing physical activity may play an important role in the prevention and management of LUTS/BPH

\section{Authors' contributions}

1. A. Z. Khudhur: literature search, concept and research design, writing the manuscripts

2. AAD. H. Al-Dabbagh: concept and research design, data analysis and interpretation, editing manuscripts, supervising the edited manuscripts

\section{Acknowledgments}

We thank our colleagues and staff in AlMustansiriyah University/College of Medicine/Department of surgery and Al-Yarmouk Teaching Hospital for supporting and preparing this article

\section{Conflict of interest}

None

\section{Funding}

None

\section{References}

1. Roehrborn CG, Siami $P$, Barkin J, Damião $R$, Becher $E$, Miñana $B$, et al. The influence of baseline parameters on changes in international prostate symptom score with dutasteride, tamsulosin, and combination therapy among men with symptomatic benign prostatic hyperplasia and an enlarged prostate: 2-year data from the CombAT study. European urology. 2009 Feb 28; 55(2):461-471.

2. Unnikrishnan $\mathrm{R}$, Almassi $\mathrm{N}$ and Fareed $\mathrm{K}$. Benign prostatic hyperplasia: evaluation and medical management in primary care . Cleveland Clinic Journal of Medicine 2017; 84(1): 53-64.

3. Fitzpatrick JM. The natural history of benign prostatic hyperplasia. BJU Int. 2006; 97(suppl 2): 3-6

4. Emberton M, Cornel EB, Bassi PF, et al. Benign prostatic hyperplasia as a progressive disease: a guide to the risk factors and options for medical management. Int $\mathrm{J}$ Clin Pract. 2008; 62: 1067-86

5. Ito $\mathrm{H}$, Yokoyama O. Metabolic syndrome and lower urinary tract symptoms. World Journal Clinical Urology. 2014; 3(3):330335.

6. Yeh HC, Liu CC, Lee YC, Wu WJ, Li WM, Li CC, Hour TC, Huang CN, Chang CF, Huang SP. Associations of the lower urinary tract symptoms with the lifestyle, prostate volume, and metabolic syndrome in the elderly males. The Aging Male. 2012 Sep 1; 15(3):166-172.

7. Aktas BK, Gokkaya CS, Bulut S, Dinek M, Ozden C, Memis A. Impact of metabolic syndrome on erectile dysfunction and lower urinary tract symptoms in benign prostatic hyperplasia patients. The Aging Male. 2011 Mar 1; 14(1):48-52.

8. Demir O, Akgul K, Akar Z, Cakmak O, Ozdemir I, Bolukbasi A, Can E, Gumus BH. Association between severity of lower urin- 
ary tract symptoms, erectile dysfunction and metabolic syndrome. The Aging Male. 2009 Jan 1; 12(1):29-34.

9. Dahle SE, Chokkalingam AP, Gao YT, Deng J, Stanczyk FZ, Hsing AW. Body size and serum levels of insulin and leptin in relation to the risk of benign prostatic hyperplasia. J Urol 2002; 168: 599-604.

10. Gassi M, Vignozzi L, Sebastianelli A, et al. Metabolic syndrome and lower urinary tract symptoms: the role of in flammation. Prostate Cancer Prostatic Dis. 2013; 16: 101-6

11. Fusco F, D'Anzeo $G$, Sessa $A$, et al. BPH/LUTS and ED: common pharmacological pathways for a common treatment. The journal of sexual medicine .2013; 10:2382-2393.

12. Ozden C, Ozdal OL, Urgancioglu G, Koyuncu H, Gokkaya S, Memis A, Seitz C, Witjes WP. The correlation between metabolic syndrome and prostatic growth in patients with benign prostatic hyperplasia. European urology. 2007 Jan 1;51(1):199206.

13. Hammarsten J, Hggstedt B, Holthuis N, Mellstrom D. Components of the metabolic syndrome-risk factors for the development of benign prostatic hyperplasia. Prostate Cancer Prostatic Dis 1998; 1: 157-62.

14. Favilla V, Cimino $S$, Salamone $C$, Fragalà $\mathrm{E}$, Madonia M, Condorelli R, et al. Risk factors of sexual dysfunction after transurethral resection of the prostate (TURP): A12 months follow-up. Journal of endocrinological investigation. 2013 Dec 1;36(11):1094 $-1098$.

15. Crawford ED, Wilson SS, McConnell JD, Slawin KM, Lieber MC, Smith JA, Meehan AG, Bautista OM, Noble WR, Kusek JW, Nyberg LM. Baseline factors as predictors of clinical progression of benign prostatic hyperplasia in men treated with placebo. The Journal of urology. 2006 Apr 1;175(4): 1422-7.

16. Expert Panel on Detection E. Executive summary of the Third Report of the National Cholesterol Education Program (NCEP) expert panel on detection, evaluation, and treatment of high blood cholesterol in adults (Adult Treatment Panel III). Jama. 2001 May 16; 285(19):2486.

17. Cruz F, Desgrandchamps F. New concepts and pathophysiology of lower urinary tract symptoms in men. European Urology Supplements. 2010 Jul 31; 9(4):472-476.
18. Ford ES, Giles WH, Dietz WH. Prevalence of the metabolic syndrome among US aduIts: findings from the third National Health and Nutrition Examination Survey. JAMA 2002; 287: 356-9

19. Parsons JK, Sarma AV, Mc Vary K, Wei JT. Obesity and benign prostatic hyperplasia: clinical connections, emerging etiological paradigms and future directions. J Urol 2009; 182; 527-31

20. Issa MM and Regan TS. Medical therapy for benign prostate hyperplasia present and future impact. The American journal of managed care .2007; 13: 4-9.

21. Hammarsten J, Högstedt B. Hyperinsulinemia as a risk factor for developing benign prostatic hyperplasia. European urology. 2001; 39:151-158.

22. Parsons JK, Carter HB, Partin AW, et al. Metabolic factors associated with benign prostatic hyperplasia. The Journal of Clinical Endocrinology \& Metabolism. 2006;91:2 562-2568.

23. Hammarsten J, Damber JE, Karlsson M, et al. Insulin and free oestradiol are independent risk factors for benign prostatic hyperplasia. Prostate cancer and prostatic diseases. 2009; 12:160-165.

24. Dahle SE, Chokkalingam AP, Gao YT, Deng J, Stanczyk FZ, Hsing AW. Body size and serum levels of insulin and leptin in relation to the risk of benign prostatic hyperplasia. The Journal of urology. 2002; 168:599-604.

25. Gupta A, Gupta S, Pavuk M, Roehrborn CG. Anthropometric and metabolic factors and risk of benign prostatic hyperplasia: a prospective cohort study of air force veterans. Urology 2006; 68: 1198-1205

26. De Nunzio C, Cindolo L, Gacci M, Pellegrini F, Carini M, Lombardo R, et al. Metabolic syndrome and lower urinary tract symptom$s$ in patients with benign prostatic enlargement: a possible link to storage symptoms. Urology. 2014 Nov 30;84(5):1181-1187.

27. Hammarsten J, Peeker R. Urological aspects of the metabolic syndrome. Nature Reviews Urology. 2011 Sep 1; 8(9):483-494.

28. Kirby MG, Wagg A, Cardozo L, Chapple C, Castro-Diaz D, De Ridder D et al. Overactive bladder: Is there a link to the metabolic syndrome in men? Neurourology and urodynamics. 2010 Nov 1;29(8):13601364. 
29. Pan JG, Liu M, Zhou X. Relationship between lower urinary tract symptoms and metabolic syndrome in a Chinese male population. Journal of endocrinological investigation. $2014 \mathrm{Apr}$ 1;37(4):339-344.

30. Yang TK, Hsieh JT, Chen SC, Chang HC, Yang $\mathrm{HJ}$, Huang $\mathrm{KH}$. Metabolic syndrome associated with reduced lower urinary tract symptoms in middle-aged men receiving health checkup. Urology. 2012 Nov 30; 80(5):1093-1097.

31. Cellek S, Rodrigo J, Lobos E, Fernández P, Serrano J, Moncada S. Selective nitrergic neurodegeneration in diabetes mellitus- a nitric oxide-dependent phenomenon. British journal of pharmacology. 1999; 128:18041812.

32. Spranger MD, Kaur J, Sala-Mercado JA, Machado TM, Krishnan AC, Alvarez A, O'Leary DS. Attenuated muscle metaboreflex-induced pressor response during postexercise muscle ischemia in renovascular hypertension. American Journal of Physiology-Regulatory, Integrative and Comparative Physiology. 2015 Apr 1;308(7): 650-658.

33. Gao Y, Wang MJ, Zhang HY, et al. Are metabolic syndrome and its components associated with lower urinary tract symptoms? Results from a Chinese male population survey. Urology. 2012; 79:194- 201. 